\title{
Secretion and effect of somatostatin in early stages of the diabetic syndrome in C57BL/KsJ-mab mice
}

\author{
J.C. Basabe, L. M. Karabatas, M. Arata, O. H. Pivetta and J.C. Cresto \\ Fundación Laboratorio de Investigaciones Pediátricas and Instituto Nacional de Genética Médica, Buenos Aires, Argentina
}

\begin{abstract}
Summary. In a previous study in C57BL/KsJ $(m d b)$ mice aged 12 to 90 days, we observed alterations in the secretion of insulin and somatostatin and in the inhibitory effect of the latter upon insulin secretion. This study explores whether hormonal alterations are to be found in the very early stages of the diabetic syndrome, i.e. between ages 4 and 12 days. The results demonstrate two distinct phases in the development of the syndrome: (a) up to age 6 days, the perifused slices of pancreata of control animals present biphasic glucose-induced patterns of insulin and somatostatin secretion, whereas the diabetic animals show a diminished first peak of insulin secretion, but a similar pattern of somatostatin secretion, to that of the control animals; (b) between ages 7 and 12 days, the pancreata of diabetic mice exhibit insulin hypersecretion in basal conditions, and an absence of the first secretion peak and in-
\end{abstract}

sulin hypersecretion in the second phase in response to glucose stimulation. The glucose-induced pattern of somatostatin secretion presents hormonal hypersecretion in both phases. Bcell sensitivity to the inhibitory effect of somatostatin is diminished in $m d b$ mice of the above-mentioned groups, an alteration which becomes more evident as diabetes evolves. The results show that, in very early stages of the evolution of the diabetic syndrome in $\mathrm{C} 57 \mathrm{BL} / \mathrm{KsJ}(m d b)$ mice, there are already alterations in insulin and somatostatin secretion patterns and in the inhibitory effect of the latter on insulin secretion.

Key words: Somatostatin, C57BL/KsJ-mdb mice, insulin secretion pattern.
Expression of the autosomal recessive $(d b)$ gene in homozygous $(d b / d b) \mathrm{C} 57 \mathrm{BL} / \mathrm{KsJ}$ mice results in a diabetic syndrome which evolves in stages, with each one showing different, well-defined hormonal and metabolic features [1-3].

In a previous study [4] on $\mathrm{C} 57 \mathrm{BL} / \mathrm{KsJ}(d b / d b)$ mice aged 12 to 90 days, we observed: a) basal and glucosestimulated insulin hypersecretion, with absence of the first secretion peak; b) somatostatin secretion patterns showing hormonal hyper-, normo- and hyposecretion, together with altered secretion dynamics; and c) diminished B-cell sensitivity to the inhibitory effect of somatostatin, which gradually became more noticeable as animals grew older.

Considering these results, we have investigated whether the above-mentioned alterations occur in very early stages (ages 4 to 12 days), or whether they are to be found during the later evolution of the diabetic syndrome in $\mathrm{C} 57 \mathrm{BL} / \mathrm{Ks} \mathrm{J}-m d b$ mice.

\section{Materials and methods}

\section{Animal model}

Members of the original C57BL/KsJ-mdb strain from the Jackson Laboratory (Bar Harbor, Maine, USA), were maintained by brother and sister mating $(F . ?+16)$ at the Instituto Nacional de Genética Médica. Mice of the C57BL/KsJ strain with the misty coat colour gene $(m)$ and diabetes $(d b)$ in coupling were used. Diabetes $(d b)$ is autosomal recessive [1], and the $d b$ locus is linked to the misty $(m)$ coat colour gene in particular. The diabetes $(d b)$ allel is in Chromosome 4 , linkage group VIII, $1.40 \pm 0.74$ recombinant units away from the misty $(m)$ allel [5]. Misty and diabetes in coupling on the same chromosome of the pair were used for a marker, since mice homozygous for both genes $(m d b / m d b)$ can be distinguished by their grey colour at age 2-4 days. On the other hand, incorporating $m$ gene does not modify the developmental features of the diabetic syndrome [2].

Normal homozygous and heterozygous carriers $(1 / 3++1++$ and $2 / 3 m d b /++$ genotypes) aged 4 to 12 days were used as controls and were designated as lean mice. It is necessary when using these groups as control, to know if this genotypically heterogenous population is a homogeneous one regarding insulin and somatostatin secretion. A test to determine variance equality (homoscedasticity) between the control group and the mutant group and between the control group and $\mathrm{BALB} / \mathrm{c}$ mice was done. BALB/c mice were chosen because they are a genotypically population free of known deletereous mutations. Homoscedasticity did not allow the detection of an heterogeneous composition in our control group.

\section{Experimental models of the pancreas}

Incubation of pancreas slices. The technique described by Martin and Bambers [7] was used. Krebs-Ringer bicarbonate was used as the incubation buffer. The medium was supplemented with $1 \%$ bovine albumin fraction V; $3.3 \mathrm{~m} \mathrm{~mol} / 1$ glucose and $1000 \mathrm{KIU}$ Trasylol $/ \mathrm{ml}$ (Bayer, Buenos Aires, Argentina). The pH of the buffer (kept under constant $95 \% \mathrm{O}_{2}, 5 \% \mathrm{CO}_{2}$ gassing) was 7.38-7.40.

In order to assess the inhibitory effect of somatostatin (SRIF) on insulin secretion, pancreas slices of both lean and diabetic mice were incubated. If the insulin secretion elicited by glucose plus somatostatin in the incubation medium was subtracted from the amount of glucose induced insulin secretion, we obtained the amount of insulin inhibited by the corresponding somatostatin concentration.

Perifusion of pancreas slices. The technique described by Burr et al. [8] were used. Proteolytic effects on hormone secretion during either incubation or perifusion were avoided by adding Trasylol to the buffer and collecting the samples on $0.25 \mathrm{~mol} / 1$ EDTA, in tubes at $4^{\circ} \mathrm{C}$ which were immediately frozen at $-20^{\circ} \mathrm{C}$. The perifusion technique provides recovery of added synthetic SRIF amounting to $91 \pm 3 \%$ (3-40 min of perifusion) and $89 \pm 3 \%$ (31-61 min of perifusion). Fol- 
lowing an initial $15-\mathrm{min}$ recuperation period, $27.5 \mathrm{mmol} / 1$ glucose stimulation started on the third min and lasted until the end of perifusion. The first 2 min were used for baseline determinations. Thin slices from the whole pancreas of a single mouse were used in each perifusion. Total pancreatic weights in $m d b / m d b$ did not differ significantly from those found in lean mice (aged 4 6 days: $3.18 \pm 0.58 \mathrm{mg} \mathrm{wt}$, lean mice $(n=7)$ versus $2.37 \pm 0.41 \mathrm{mg}$ wt, $m d b / m d b(n=12)$; aged 7 12 days : $4.55 \pm 0.27 \mathrm{mg}$ wt, lean mice $(n=12)$ versus $4.52 \pm 0.30 \mathrm{mg} \mathrm{wt}$, $m d b / m d b(n=14))$.

Insulin and SRIF radioimmunoassay. Insulin was determined by the method of Herbert et al. [9], and modified by Cresto et al. [10]. SRIF was assayed with the technique of Arimura et al. [11]. Antiserum I 650 against SRIF, SRIF standard and (Tyr ${ }^{\mathrm{l}}$ )-SRIF were obtained from UCB Bioproducts (Brussels, Belgium). The sensitivity of the assay, calculated as the least amount of SRIF causing a displacement of 2 standard deviations from $B_{0}$, was $1.5-2.0$ pg per tube; different samples or pools of sample dilutions were parallel to the standard curve. The intra-assay variation (samples containing $75-200 \mathrm{pg} / \mathrm{ml}$ ) was $7.9 \%$; the inter-assay coefficient (samples containing $70-200 \mathrm{pg} / \mathrm{ml}$ ) was $9.8 \%$. At a final dilution of $1 / 4900$, SRIF antiserum binds $40 \%$ of ${ }^{125} \mathrm{I}_{-} \mathrm{Tyr}_{1}$-SRIF. Neither insulin, glucagon, pancreatic polypeptide nor gastrin used in the standard curve displaced $\left({ }^{125} \mathrm{I}\right) \mathrm{Tyr}_{1}$-SRIF from the antiserum under radioimmunoassay condition. Mean recovery of SRIF added to the RIA was $96.3 \%$.

Plasma glucose was determined by a colorimetric enzymatic method from Wiener Laboratories (Buenos Aires, Argentina) in a Beckman DB-G spectrophotometer.

\section{Statistical analysis}

Statistical analysis of the data was performed with two-tailed Student's $t$-test for unpaired samples.

\section{Results}

Plasma glucose values at the time of the experiment show no significant differences between diabetic and lean mice: $++/$ ??: $4.16 \pm 0.34 \mathrm{~m} \mathrm{~mol} / 1, n=5$, versus $m d b / m d b: 4.34 \pm 0.33 \mathrm{~m} \mathrm{~mol} / 1, n=6 ; p:$ NS.

The results obtained concerning insulin and somatostatin secretion patterns led us to consider two experimental groups: (a) diabetic and lean mice aged 4 to 6 days; (b) diabetic and lean animals aged 7 to 12 days.

\section{Insulin secretion}

Mice aged 4 to 6 days. As it can be seen in Figure 1, both diabetic and lean mice showed a biphasic pattern in the presence of $27.5 \mathrm{~m} \mathrm{~mol} / 1$ glucose stimulation. In our experimental conditions, the first secretion peak reaches its highest level at perifusion time $6 \mathrm{~min}$, while the second phase rises to its highest value at perifusion time $40 \mathrm{~min}$. Basal insulin levels in the $m d b / m d b$ $\left(1.24 \pm 0.16 \mathrm{ng} \cdot \mathrm{min}^{-1} \cdot 100 \mathrm{mg} \mathrm{wt}^{-1}, n=6\right)$ do not differ significantly from those found in lean mice $(1.08 \pm$ $\left.30.11 \mathrm{ng} \cdot \mathrm{min}^{-1} \cdot 100 \mathrm{mg} \mathrm{wt}^{-1}, n=4\right)$. The first insulin secretion peak in $m d b / m d b$ is found to be significantly diminished when compared with lean mice values ( $m d b / m d b: 4.92 \pm 0.12 \mathrm{ng} \cdot \mathrm{min}^{-1} \cdot 100 \mathrm{mg} \mathrm{wt}^{-1}, n=6$ versus $++/ ? ?: 6.40 \pm 0.52 \mathrm{ng} \cdot \mathrm{min}^{-1} \cdot 100 \mathrm{mg} \mathrm{wt}{ }^{-1}$, $n=4 ; p<0.01$, perfusion time: $6 \mathrm{~min}$ ). Insulin levels corresponding to the second secretion phase are not significantly different in both groups studied ( $p$ : NS).

Mice aged 7-12 days. The lean mice showed a biphasic secretion pattern elicited by $27.5 \mathrm{~m} \mathrm{~mol} / 1$ glucose. In
Figure 2 we can also observe that, as compared with lean mice, the diabetic mice present: (a) basal insulin hypersecretion ( $p<0.001, n=5$, in both cases); (b) insulin hypersecretion corresponding to the second phase ( $p<0.05 ; n=5$, with values corresponding to perifusion time 40 min in both cases); (c) a lack of the first peak of glucose-induced insulin secretion, since the levels reached did not differ significantly from basal values.

\section{Somatostatin secretion}

Mice aged 4 to 6 days. As shown in Figure 3, secretion patterns in diabetic and lean mice show biphasic profiles in their response to $27.5 \mathrm{~m} \mathrm{~mol} / 1$ glucose stimulation which are not significantly different. In both cases, the first secretion peak reaches its highest value at perfusion time $5 \min (n=4$ and 5 respectively; $p$ : NS). The second phase reaches its highest value at perifusion time $40 \mathrm{~min}$ ( $n=3$ and 4 respectively; $p$ : NS).

Mice aged 7 to 12 days. In Figure 4 it can be observed that both diabetic and lean mice maintain a biphasic secretion pattern elicited by $27.5 \mathrm{~m} \mathrm{~mol} / 1$ glucose. There

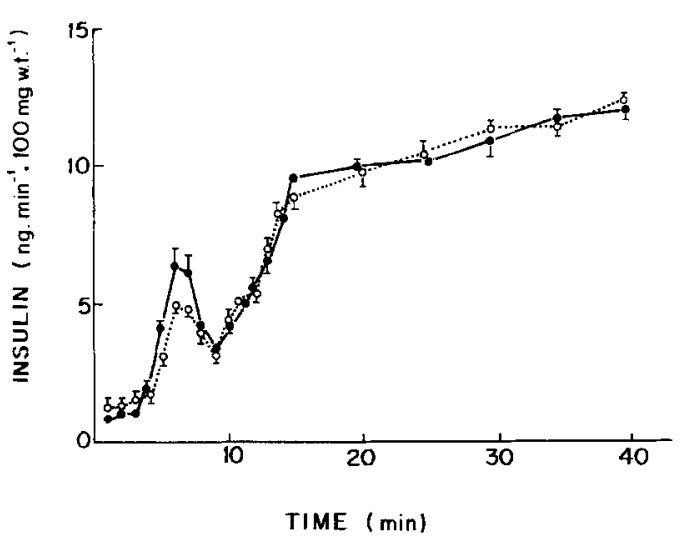

Fig. 1. Insulin secretion elicited by $27.5 \mathrm{~m} \mathrm{~mol} / 1$ glucose in perifused pancreatic slices from lean $(\longrightarrow),(n=6)$, and $m d b / m d b$ (O.... 0$),(n=4)$, mice aged 4 to 6 days. Each point represents the mean \pm SEM

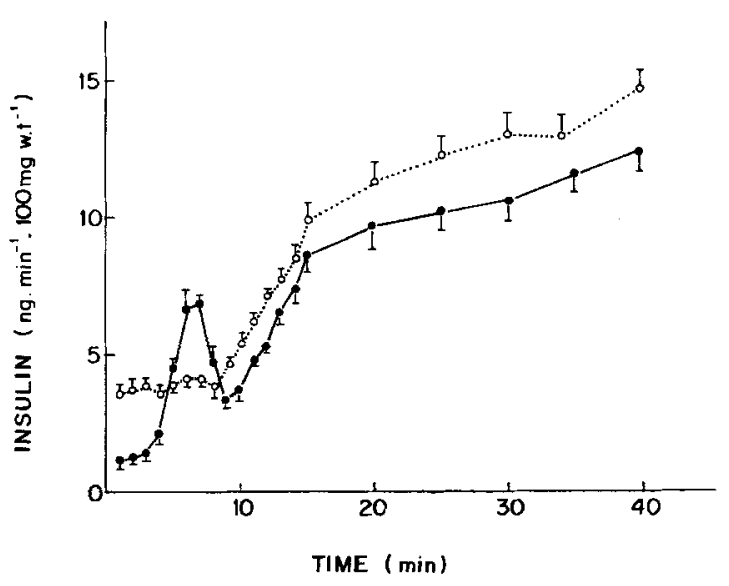

Fig. 2. Insulin secretion in perifused pancreatic slices from lean $(-1),(n=5)$, and $m d b / m d b\left(O-O_{0}\right),(n=5)$, mice aged 7 to 12 days. Results are given as mean \pm SEM 


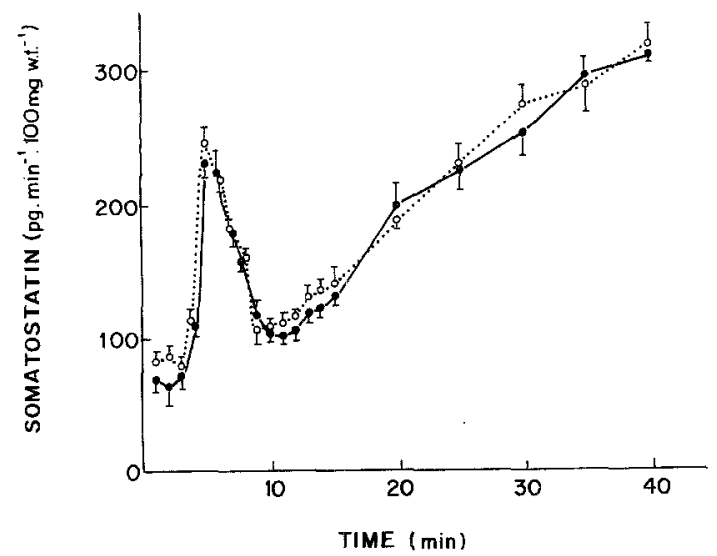

Fig. 3. Amounts of somatostatin secreted by perifused pancreatic slices of: lean (-) and $m d b / m d b(\mathrm{O}-.-\mathrm{O})$ mice aged 4 to 6 days. Results are expressed as mean \pm SEM

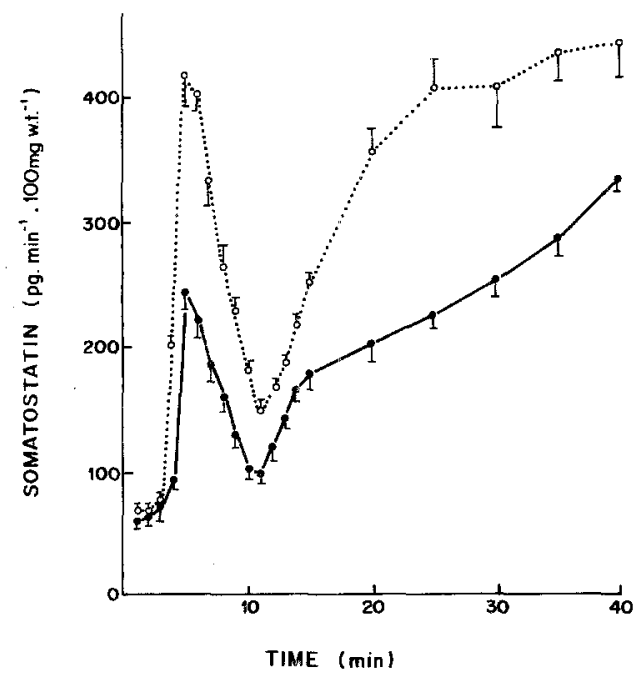

Fig.4. Somatostatin secretion in perifused pancreatic slices from lean $(-\infty),(n=6)$, and $m d b / m d b(\bigcirc-\ldots),(n=6)$, mice aged 7 to 12 days. Results are given as mean \pm SEM

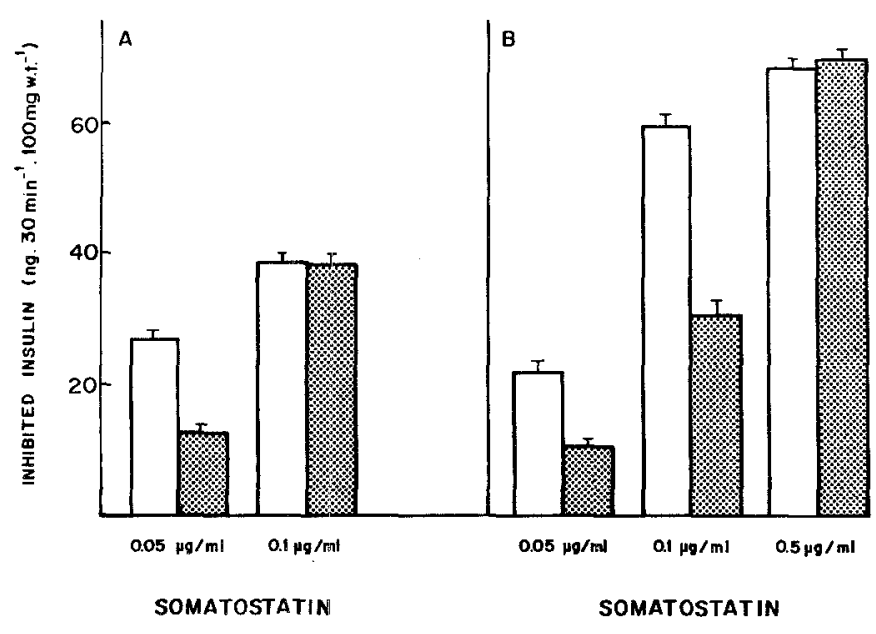

Fig. 5A and B. Amounts of insulin inhibited by exogenous somatostatin in incubated pancreatic slices from lean $\square$ and $m d b / m d b$ mice. Results are given as mean \pm SEM. A Mice aged 4 to 6 days; B Mice aged 7 to 12 days are no significant differences in basal secretion $(n=6$; $p$ : NS). The diabetic animals present somatostatin hypersecretion in both phases: first phase (maximum at $\min 5$ ), and second phase (maximum at perfusion time $40 \mathrm{~min}, n=6$ and 5 respectively, $p<0.01$ in both phases).

\section{$B$-cell sensitivity to the inhibitory effect of somatostatin}

In mice aged 4-6 days, with $0.05 \mu \mathrm{g} / \mathrm{ml}$ somatostatin concentrations in the incubation medium, the amount of inhibited insulin in the diabetic mice is significantly lower than that in the lean mice (Fig. $5 ; n=6 ; p<0.01$ ). When the somatostatin concentration is $0.10 \mu \mathrm{g} / \mathrm{ml}$, the inhibitory effect of this hormone is similar for both groups of mice $(n=4 ; p: \mathrm{NS})$.

In the 7 to 12 days old animals the inhibitory effect of somatostatin in 0.05 and $0.10 \mu \mathrm{g} / \mathrm{ml}$ concentrations is less in diabetic mice than in lean mice $(p<0.01$ and $<0.001$ respectively).

On the other hand, the same amount of inhibited insulin is obtained in lean and in diabetic animals with somatostatin concentrations of $0.50 \mu \mathrm{g} / \mathrm{ml}$ in the incubation medium ( $n=3$ in both groups; $p$ : NS).

\section{Discussion}

In a previous paper, $m+/+d b$ perifused islets from adult mice were reported to be defective in comparison to $m+/ m+$ controls, as an effect of the $d b$ gene in the heterozygous state [6]. The variance equality analysis, of the control group, shows that there is no difference in the insulin or somatostatin secretion patterns in our own linkage stock $(m d b /++$ or $++/++)$.

$\mathrm{C} 57 \mathrm{BL} / \mathrm{KsJ}-m d b$ diabetic mice aged $4-6$ days show normal basal insulin secretion. In the diabetic groups aged 7-12 days basal insulin hypersecretion was observed. Basal $\mathrm{K}^{+}$permeability was reported to be diminished in B cells; this would lead to a persistent depolarization of the plasma membrane at low glucose concentration, and might explain the increased basal insulin secretion $[12,13]$.

The basal insulin hypersecretion diabetic mice aged 7-12 days, and the finding that plasma glucose of diabetic mice exhibits values similar to those of lean mice, might suggest a peripheral resistence to insulin. These results agree with the findings of Coleman [2], who reported hyperinsulinemia in $m d b / m d b$ mice older than 10 days.

The results show that the earliest detectable alteration (diabetic mice aged 4 to 6 days) is a decrease in the first phase of glucose-induced insulin secretion. Later (7 to 12 days), the pattern of insulin secretion is qualitatively similar to that found in later stages [4]. However, the data do not elucidate whether the $d b$ mutation affected the B cells directly or that the increasing abnormal secretion patterns were in response to other factors in the post-weaning environment. 
In the earliest stages studied, we can observe diminished B-cell sensitivity to the inhibitory effect of somatostatin. This lesser sensitivity persists and becomes more evident in later stages of the diabetic syndrome [4]. Thus, it is necessary to keep increasing to exogenous somatostatin concentrations in order to attain a similar inhibition of insulin secretion between $m d b$ and lean mice. Pace et al. [14] reported evidence from electrophysiologic and cationic flux studies indicating that somatostatin may activate $\mathrm{K}^{+}$permeability as its primary mode of action, an event that may be sufficient to reduce the accumulation of intracellular $\mathrm{Ca}^{2+}$ and thereby disrupt glucose-induced insulin secretion. Failure of this mechanism might explain the diminished Bcell sensitivity to the inhibitory effect of somatostatin detected in $\mathrm{KsJ}-m d b$ mice.

Somatostatin secretion is normal in diabetic mice up to 6 days old, whereas diabetic animals aged 7-12 days exhibit glucose-induced hypersecretion. This agrees with Berelowitz et al. [3] who found that diabetic (C57BL/KsJ) mice, after 10 weeks, showed an age-dependent increase in pancreatic SRIF content and concentration.

The data on somatostatin secretion pattern show that their alteration follows the occurrence of alterations in insulin secretion and in the inhibitory effect of somatostatin. Leiter et al. [15] have reported that 8- to 10-week-old diabetic mice present morphological and topographical alterations in the islet delta cells. These authors postulated that such changes in delta cells might operate compensatorily to restore their volume density after B-cell hyperplasia. Our results suggest that somatostatin secretion could be modified before any changes occur in the morphology and topography of the islets.

The temporal relationship of detected hormonal alterations shows, in mice aged 4 to 6 days, a diminished insulin secretion (first phase) and a decreased B-cell sensitivity to somatostatin. In mice aged 7 to 12 days the first phase of glucose-induced insulin secretion is not observed, whereas the diminished sensitivity to somatostatin becomes more evident. Further studies are needed to determine to what extent the failure in the first phase insulin secretion might be related to a diminished sensitivity to the inhibitory effect of somatostatin.

Sussman et al. [16] have reported that during emiocytosis there occurs a migration of secretory vesicles in the B cell which might also carry somatostatin receptors from some intracellular pool (secretory granule) to the plasma membrane. This leads us to consider the possibility that, in our experimental model, the diminished insulin secretion would imply a decrease in the number of somatostatin receptors on the B-cell surface. This would help to explain the decreased sensitivity to the inhibitory effect of somatostatin observed in diabetic mice.

Our results are also compatible with the possibility that abnormal insulin secretion may lead to a general dysfunction of the islet of Langerhans.
Acknowledgements. We gratefully acknowledge the technical assistance of Ms. M.C.de Cornet and Ms. P.I.Castellani, and the secretarial help of Ms. S. Paz and Ms. N. Labriola. We also wish to express our thanks to Dr. R.R. Gutman for supplying the anti-insulin antibody. Trasylol was a generous gift form Bayer Argentina. This work was supported by grants from the Nordisk Foundation, Fundación Alberto J.Röemmers, and by grants No.2305/k, 2305/1 of CONICET, and 10253/82-9 and 106183/83-6 of SECYT, Argentina.

\section{References}

1. Coleman DL, Hummel KP (1967) Studies with the mutation diabetes in the mouse. Diabetologia 3: 238-248

2. Coleman DL, Hummel KP (1974) Hyperinsulinemia in the preweaning diabetes $(\mathrm{db})$ mice. Diabetologia 10: 607-610

3. Berelowitz M, Coleman DL, Frohman L (1980) Temporal relationship of tissue somatostatin-like immunoreactivity to metabolic changes in genetically obese and diabetic mice. Diabetes 29: 717-723

4. Basabe JC, Pivetta OH, Fabiano de Bruno L, Cresto JC, Aparicio NJ (1983) A temporal study of somatostatin secretion and its inhibitory effect in genetically diabetic mice (C57BL/KsJ-db/db). Endocrinology 113: 1927-1934

5. Hummel KP, Coleman DL, Lane PW (1972) The influence of genetic background on expression of mutations at the diabetes locus in the mouse. I. C57BL/KsJ and C57BL/6J strains. Biochem Genet 7: 1-13

6. Molina JM, Premdas FH, Klenck RE, Eddlestone G, Oldham SB, Lipson LG (1984) The dynamic insulin secretory response of isolated pancreatic islets of the diabetic mouse. Diabetes 33: $1120-1123$

7. Martin JM, Bambers G (1965) Insulin secretion in glucosamineinduced hyperglycemia in rats. Am J Physiol 209: 797-803

8. Burr IM, Stauffacher W, Balant L, Renold AE, Grodsky GM (1969) Regulation of insulin release in perifused pancreatic tissue. Acta Diabet Lat 6: 580-596

9. Herbert V, Lau K, Gottlieb CW, Bleicher SJ (1965) Coated charcoal immunoassay of insulin. J Clin Endocrinol Metab 25: 1375-1384

10. Cresto JC, Dujovne I, Castellani PI, Mitta EA, de Majo SF, Foglia VG (1972) Insulin radioimmunoassay by the charcoal-dextran technique. Diabetologia 8: 292-295

11. Arimura A, Sato H, Coy D, Schally A (1975) Radioimmunoassay for GH-release inhibiting hormone. Proc Soc Exp Biol Med 148: 784-789

12. Berglund O, Sehlin J, Taljedal IB (1980) Influence of the murine diabetes gene on rubidium ion efflux from perifused islets. Diabetologia 19: 45-49

13. Berglund $\mathrm{O}$ (1981) Disturbed fluxes of $\mathrm{Rb}^{+}\left(\mathrm{K}^{+}\right)$and $\mathrm{Cl}^{-}$in islets of spontaneously diabetic mice (C57BL/Ks J-db/db). Acta Biol Med Germ 40:23-30

14. Pace CS, Tarvin JT (1981) Somatostatin: Mechanism of action in pancreatic islet $\beta$-cells. Diabetes 30: 836-842

15. Leiter EH, Gapp DA, Eppig JJ, Coleman DL (1979) Ultrastructural and morphometric studies of delta cells in pancreatic islets from C57BL/KsJ diabetic mice. Diabetologia 17:297-309

16. Sussman KE, Mehler PS, Wayne Leitner J, Draznin B (1982) Role of the secretion vesicle in the transport of receptors: modulation of somatostatin binding to pancreatic islets. Endocrinology 111: 316-323

Received: 2 July 1985

and in revised form: 16 June 1986

\section{Dr. J.C. Basabe}

Fundación Laboratorio de Investigaciones Pediátricas (FLIP)

Hospital General de Niños "Dr. Pedro de Elizalde"

Montes de Oca 40

1270 Buenos Aires

Argentina 